\title{
Technical Advancements in Living Donor Liver Transplant
}

\author{
Shashwat Sarin ${ }^{1}$, Ramazan Dönmez ${ }^{2}$, Yaman Tokat ${ }^{3 *}$ \\ 'Department of HPB Surgery and Liver Transplantation, Mahatma Gandhi Hospital and University, \\ Jaipur, India \\ ${ }^{2}$ Yeditepe University Hospital, Istanbul, Turkey \\ ${ }^{3}$ International Liver Center, Istanbul, Turkey
}

\section{ABSTRACT}

Over the past 2 decades, living donor liver transplantation has become a standard and accepted alternative to deceased donor liver transplantation, especially in countries with poor cadaveric donation rates. Numerous innovations in surgical technique along with improved understanding of post-transplant physiology have led to LDLT having comparable and sometimes exceeding outcomes of DDLT. The importance of venous outflow and adequate anterior sectoral drainage to minimize congestion has been central to improving safety and outcomes in LDLT. Portal vein thrombosis, once a contraindication to transplant is now tackled with excellent outcomes with improvement in surgical technique. Understanding of graft hemodynamics and portal flow has significantly increased the graft pool with acceptance of smaller grafts without lowering patient outcomes. Portal flow modulation techniques are routinely being used to minimize graft injury secondary to portal hypertension and the development of small for size syndrome. Innovative techniques for biliary reconstruction have been devised in a bid to minimize biliary complications. Adoption of microsurgical techniques to arterial reconstruction and utilization of extra anatomic arterial inflow has led to significant shrinkage of grafts lost to hepatic arterial dissection and thrombosis. This review highlights a number of technical advancements made in the field of liver transplant surgery made over the past decade; especially focusing on living donor transplantation.

Key words: Living donor liver transplant, biliary reconstruction, portal vein thrombosis, arterial reconstruction, MHV, inflow modulation.

The success of liver transplantation over the past few decades has propelled transplantation as the standard of care for end stage liver disease, acute liver failure and hepatic malignancies. The expanding indications of transplant are limited only because of a continued paucity of donor organs. Surgeons are constantly innovating to increase the potential donor pool and consistently improve recipient and donor outcomes. This review focuses on numerous technical advancements made in the field of transplant surgery over the past decade; especially focusing on technical refinements in arterial and biliary anastomosis, management of portal vein thrombosis in transplant recipients as well as recent inflow and outflow modifications.

\section{ADVANCEMENTS IN VENOUS OUTFLOW RECONSTRUCTION}

A meticulously created venous outflow is one of the four pillars of a success-

\author{
*Corresponding author: \\ Professor Yaman Tokat \\ Liver Transplantation and HPB Center \\ Florence Nightingale Hospital, Istanbul \\ Turkey \\ E-mail: tokat@florence.com.tr
}

Received: 22.12.2020

Accepted: 19.02.2021 
ful living donor liver transplant; the others being adequate graft volume, sufficient inflow and a secure biliary anastomosis. Outflow obstruction leading to venous congestion of the graft leads to impaired graft function, development of a small for size syndrome, graft failure or even death, more so for smaller grafts with GRWR $<1$. For a right lobe graft, venous outflow takes place via 3 routes; the RHV, the native or neoMHV and (if present) short inferior hepatic veins. It is imperative to reconstruct each of these 3 outflows to minimize graft congestion.

The importance of adequate drainage of the anterior sector has long been recognized (1). Anterior sectoral drainage may be achieved in the form of an extended right lobe graft (ERLG) that includes the donor MHV (fig. 1) or a modified right lobe graft (MRLG) which doesn't. While an ERLG allows for perfect drainage of the anterior sector, it transfers the risk of liver congestion to the donor. Most centers now perform a MRLG, partially or completely excluding the MHV during procurement.

\section{$R H V$ reconstruction}

The RHV forms the primary outflow pathway for the right graft. The transplant surgeon must be cognizant of the fact that the outflow created must allow for unobstructed drainage not only in the immediate post transplant period, but also once the partial graft regenerates. RHV stenosis is common after graft regeneration, leading to beaking at the caudal end of the anastomosis (2). It is now therefore standard practice to incised and widen the RHV opening on the graft as well as the RHV opening on the IVC caudally prior to implantation. Certain centers also perform a hemi-circumferential augmentation patch plasty of the graft RHV to increase outflow diameter (3). The long-term patency of the RHV is as important as that of the MHV for adequate graft function.

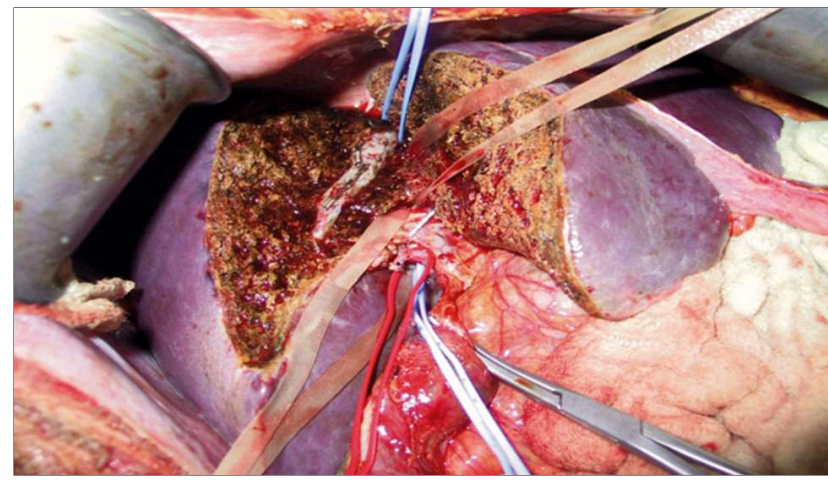

Figure 1 - Harvesting of MHV in an extended right lobe graft

\section{MHV reconstruction}

In MRGL, reconstruction of the venous drainage of the anterior sector is an integral part of back table preparation of the graft. It is strongly recommended that all veins larger than $5 \mathrm{~mm}$ draining segments 5 and 8 are reconstructed into a neo-MHV (4). A caudal slit incision of the orifices of V5 and V8 may increase the orifice diameter up to three-fold and prevent anastomotic stenosis.

The choice of venous graft for this purpose may be native tissue (internal iliac vein, umbilical vein, internal jugular vein, aorta and its branches, IVC, portal vein) or prosthetic grafts [Dacron, expanded-polytetrafluoroethylene (e-PTF)] (5-7). Patency rates in most studies are comparable between native and prosthetic grafts of $90 \%$ at 1 month and $>60 \%$ at 6 months. Long term patency of the graft is usually of limited clinical consequence. While native grafts offer the benefit of lower cost, minimal tissue reaction and no requirement for antiplatelet drugs, they are limited by their lack of widespread availability.

The RHV and neo-MHV may be anastomosed separately to the RHV, MHV-LHV orifices on the IVC (fig. 3) to form a dual outflow or joined and anastomosed as a single orifice to the IVC (figs. 4, 5). While a single orifice outflow may provide the potential benefit of a shorter warm ischemia time because of a single anastomosis, two separate outflows ensure a higher patency rate in the short (in case of early thrombosis in one outflow) and medium term (compression of outflow secondary to graft regeneration) (8).

For an ERLG outflow may similarly be reconstructed

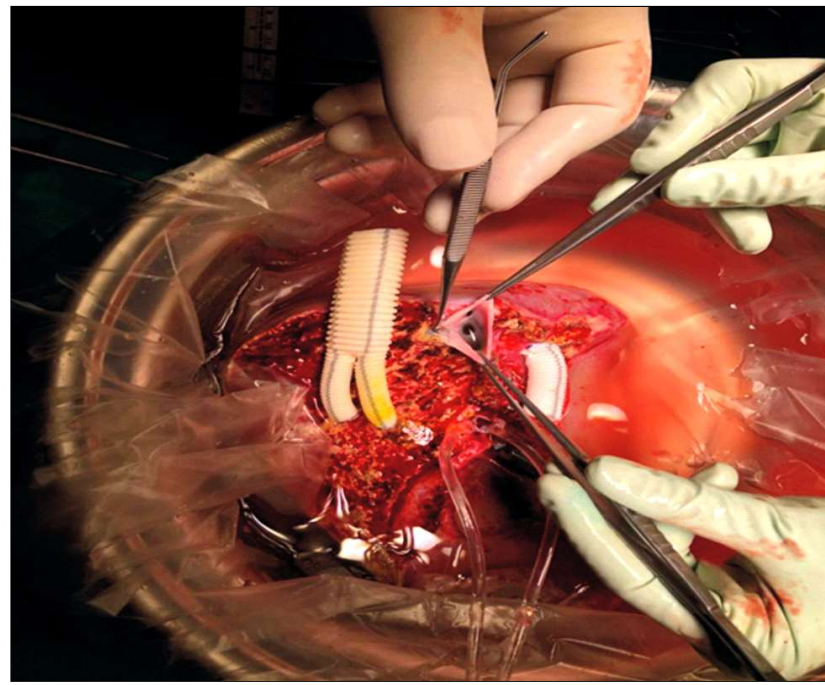

Figure 2 - Reconstruction of a Neo-MHV using a ringed Dacron graft. The RHV orifice has been incised caudally to increase circumferential outflow 


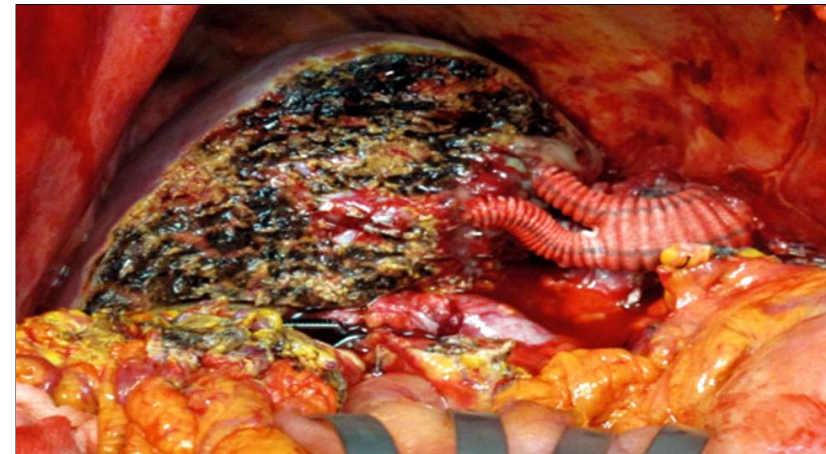

Figure 3 - Outflow reconstruction with a Y shaped Dacron graft utilized to reconstruct V5 and V8 and anastomosis to the MHV-LHV orifice. RHV to RHV anastomosis is not shown in this picture

as a singular anastomosis following a unification venoplasty of RHV-MHV followed by a direct anastomosis onto the IVC or after creation of a redundant dome shame reservoir (quilt-venoplasty) between the RHV-MHV and the IVC. Alternatively an interposition graft may be placed and the MHV anastomosed

\section{Right inferior hepatic vein (RIHV) reconstruction}

Posterior sectoral drainage is often complicated by the presence of multiple short inferior hepatic veins draining directly in to the IVC. Bench techniques to unify these smaller multiple orifices into a common, larger orifice using quilt venoplasty (fig. 6), utilization of a boat graft or a double caval technique help in easier implantation and preventing graft congestion due to IVC compression. (9)

The ERL graft may be considered in certain cases. More than 15 branches may from drain segment 5 and segment 8 into the MHV. A MRL graft with a neo MHV therefore will always provide inferior drainage compared to ERLG. Patients with severe portal hypertension, acute on chronic liver failure and high MELD scores receiving a partial liver graft would benefit from a perfect outflow. The previously published Florence Nightingale algorithm for utilizing of ERLG includes donor age $<35$ years, FLR $>30 \%$ of TLV, steatosis $<15 \%$, presence of a segment $4 \mathrm{~b}$ vein and right $A S$ veins $<5 \mathrm{~mm}$ (10).

\section{ADVANCEMENTS IN PORTAL VEIN RECONSTRUCTION}

\section{Portal vein reconstruction}

Advancements in operative technique mean variations in portal vein anatomy are rarely contraindications to liver donation. Extreme care must be taken to ensure there is no portal vein stenosis on the

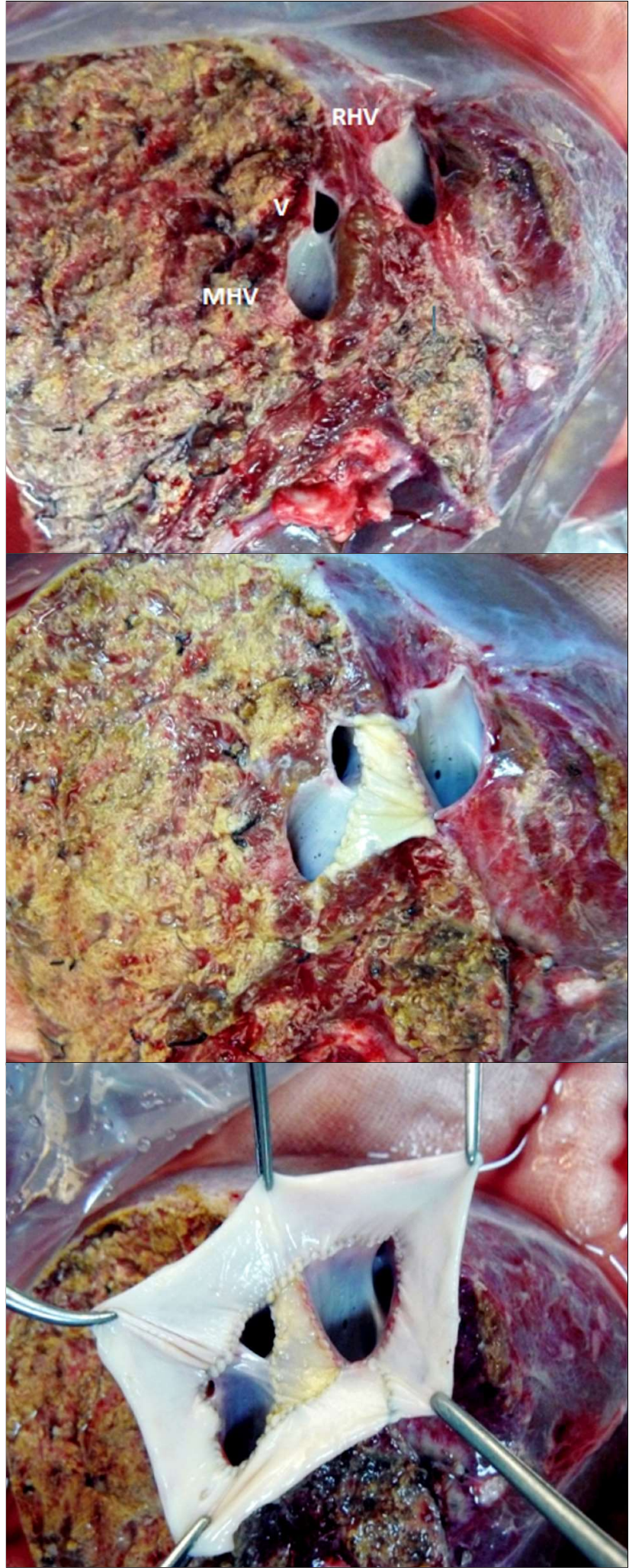

Figure 4 - Quilt venoplasty into a single orifice using a venous patch to allow for easy anastomosis into the IVC

donor side after graft excision. Multiple portal vein orifices may be reconstructed into a single outflow using a cadaveric or native (from the explanted liver) venous graft (fig. 7). 


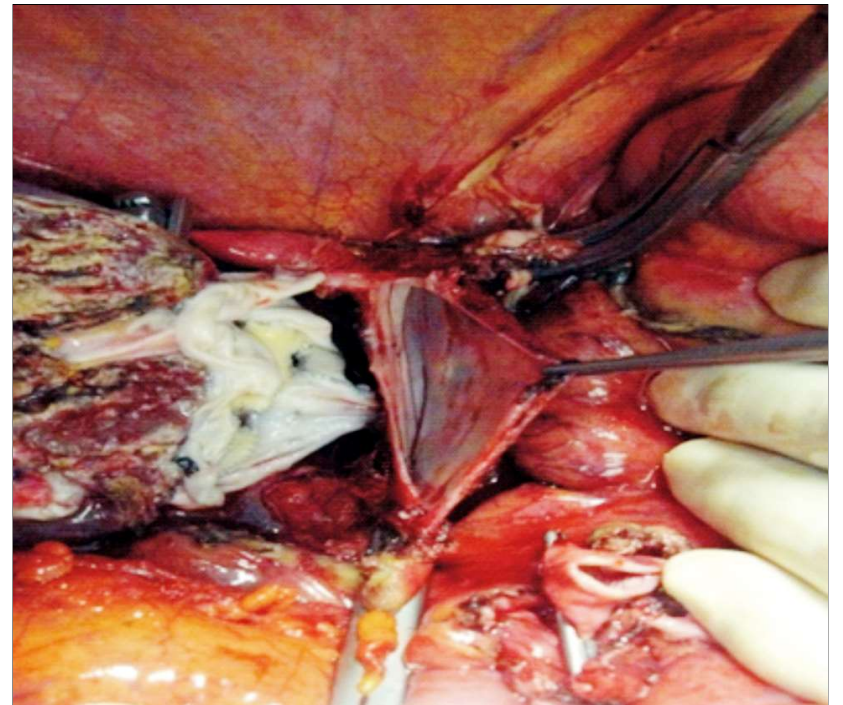

Figure 5 - Wide ostium created on the IVC just prior to reconstruction

\section{Portal vein thrombosis}

\section{Incidence and background}

The prevalence of non-tumoral portal vein thrombosis in cirrhotic patients at evaluation or at the time of transplantation ranges between $5 \%$ to $26 \%$ while a sizeable percentage develop de novo PVT while on the waiting list (11). Length of time on the waiting list, age, prior variceal bleed, ascites, $\mathrm{NASH}$, obesity and diabetes have been identified as risk factors leading to development of PVT (12-14). While initially considered an absolute contraindication to liver transplant, advancements in surgical techniques have led to patients with even complex PVT now achieving excellent outcomes (15).

\section{Preoperative treatment/optimization}

Spontaneous recanalization of PVT is rare and further progression of PVT may lead to clinical deterioration that may leave a potential recipient unfit for transplant, it is prudent to consider preoperative treatment of the PVT. Treatment may be initiated in the form of anticoagulation including low molecular weight heparin and vitamin $\mathrm{k}$ antagonists showed some element of recanalization in up to $71 \%$ of patients (fig. 8) (16). Alternatively successfully place TIPS may achieve portal recanalization in up to $80 \%$ of patients (17).

\section{Grading}

Yerdel grading is most commonly utilized to delineate the extent of thrombosis and surgical

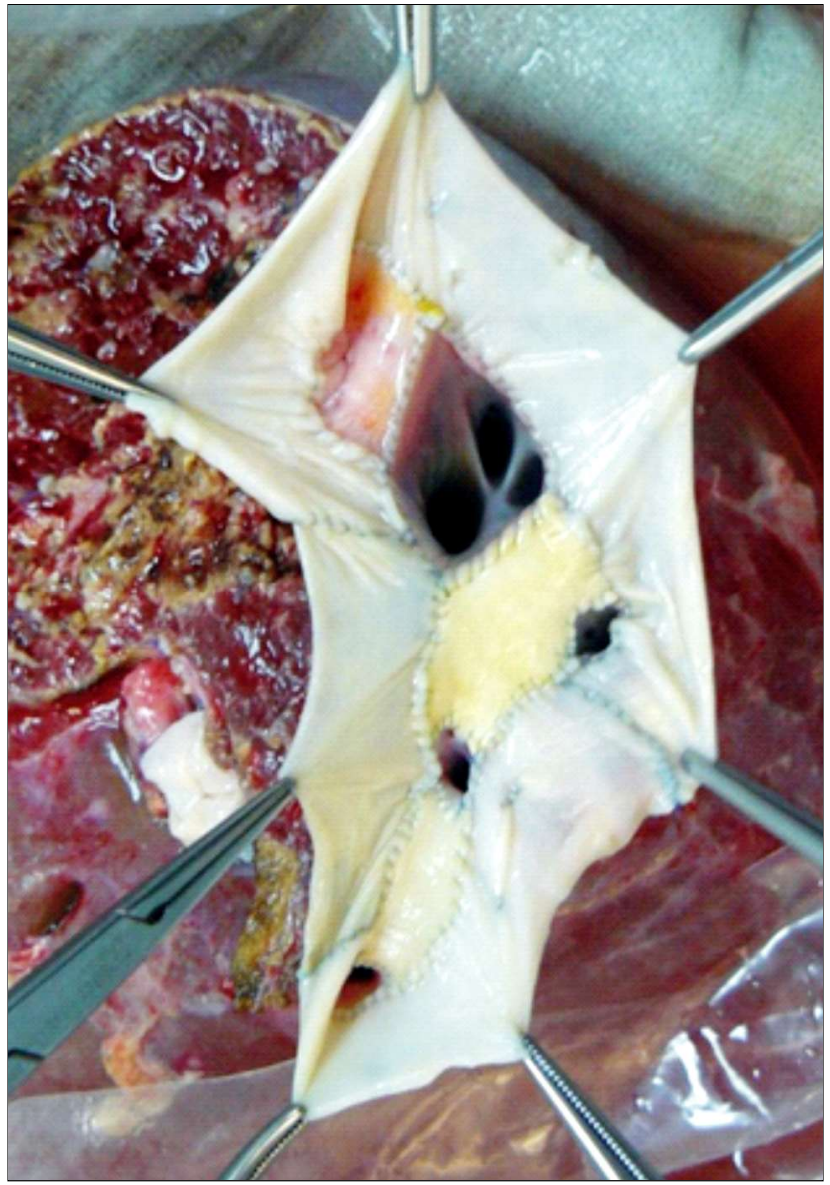

Figure 6 - Quilt venoplasty into a single orifice using multiple venous patches

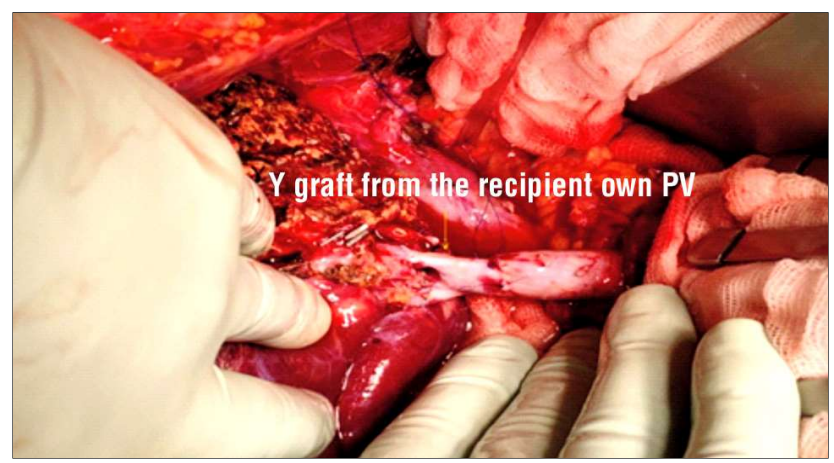

Figure 7 - Dual portal veins on the recipient side reconstructed using a $Y$ shaped graft from the recipient portal vein

management at the time of $L T$ (18). Yerdel grade I and II involve $<50 \%$ and $>50 \%$ thrombosis of the portal vein, with grade III involving thrombosis of the proximal SMV as well. While Yerdel grade IV refers to extensive mesenteric thrombosis in addition to portal thrombosis, it is not useful for guiding management. Jamieson (19) and Charco (20) provide additional information in extensive (Grade IV Yerdel) thrombosis. Grade III and Grade IV in both classifica- 


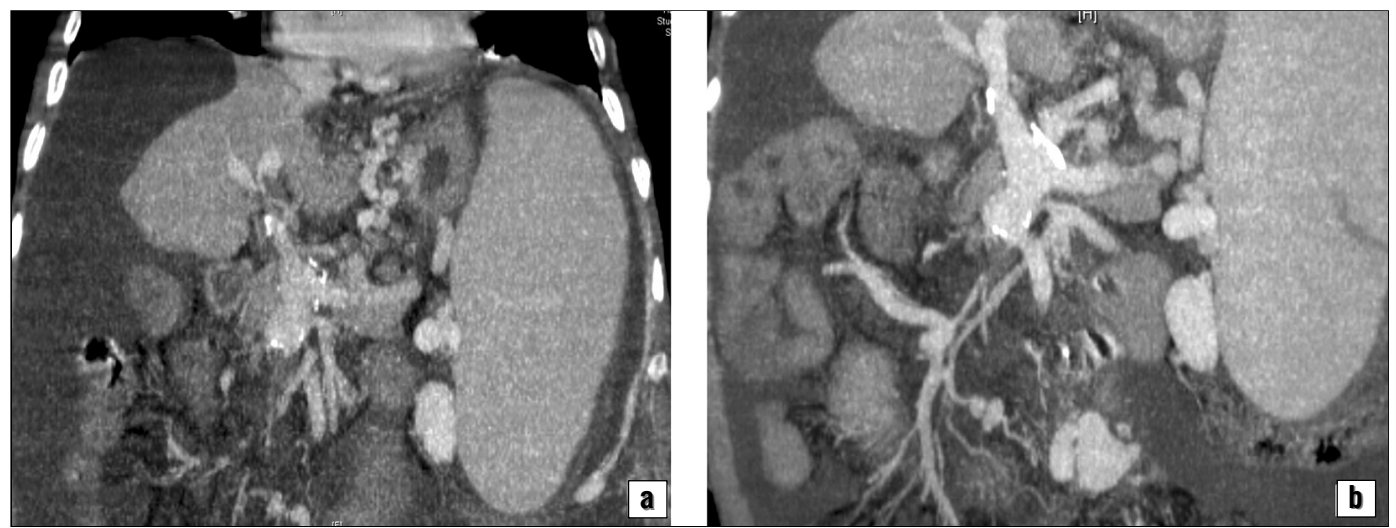

Figure 8 - Pre (a) and Post (b) CT images demonstrating recanalization of a completely thrombosed portal vein after 3 months of heparin therapy

tions refer to extensive portomesenteric thrombosis with and without large accessible collaterals respectively which impacts choice of inflow.

\section{Physiological vs non physiological inflow}

Establishment of portal inflow may be physiological in which case all or part of splanchnic blood flow is directed to the liver via anastomosis to the native portal vein, a large portosystemic collaterals or of the drainage vessel of the shunt to the IVC (21). Alternatively portal inflow may be non-physiological in the form of renoportal anastomosis in the absence of a shunt, cavoportal anastomosis and portal vein arterialization (22-24). Physiological restoration of blood flow is always preferred as it leads to resolution or reversal of portal hypertension, but non physiological inflow may actually lead to worsening of preexisting portal hypertension (25).

\section{Intra operative management}

Sound support from the anesthesia team is critical during manipulation of the thrombus and successful establishment of portal flow. Grade I and II PVT can be successfully managed with eversion thrombectomy (fig. 9) or thromboendovenectomy which involves resection of the thrombus along with the involved portion of the portal vein $(26,27)$. An insufficient length of recipient portal vein may be supplemented by utilizing an iliac vein graft or augmented saphenous vein graft (28). Before attempting any portal vein manipulation, it is essential to ensure adequate exposure of the splenomesenteric junction for safety and for completeness of the thrombectomy.

While thrombectomy may be attempted in grade III PVT, it is rarely successful because of the diffuse extension of the thrombus. It is prudent to consider a jump graft from the superior mesenteric vein and splenic or rarely the left gastric vein. The jump graft is generally taken form the anterior surface of the SMV, tunneled through the mesocolon and anastomosed end - side to the graft portal vein.

For even more extensive type IV PVT, it is essential to plan portal inflow in the preoperative stage. Physiological inflow is always preferred in the form of a reno portal anastomosis if there is presence of a pre-existing spleno renal shunt. Alternatively, a large pericholedochal varix or coronary vein may be utilized.

In the absence of pre-existing portosystemic shunts, non-physiological sources of inflow may be utilized in decreasing order of preference; renoportal anastomosis, cavo-portal anastomosis, portal vein arterialization and multivisceral transplant. A more extensive algorithm for PVT management may be found in a recent paper by Bhangui et al (21).

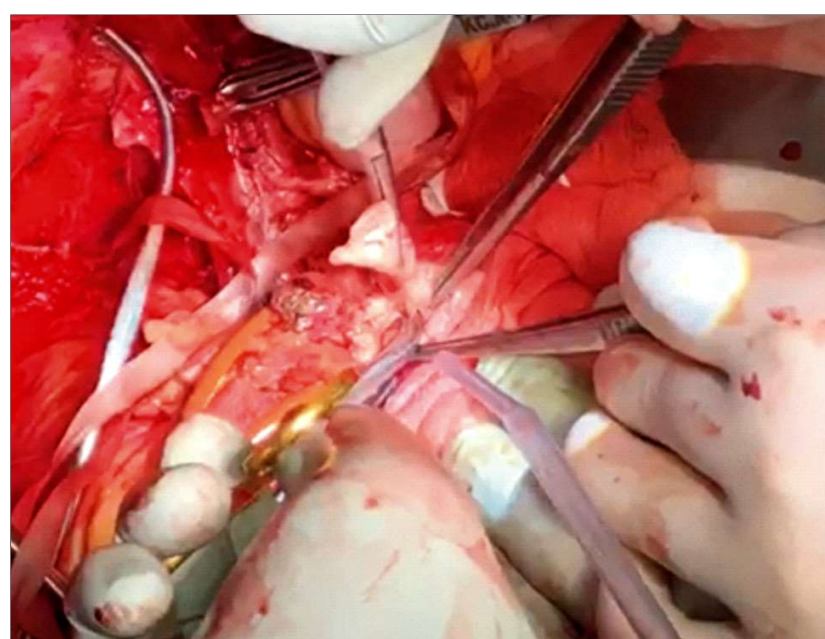

Figure 9 - Portal vein thrombectomy in a case of chronic portal vein thrombosis 
In cases where there is an unexpected intra operative finding of a PVT, it is important to differentiate between a soft fragile acute thrombus that can be easily dissected from the venous wall or a chronic calcified thrombus that is densely adhered. A detailed intra operative Doppler ultrasound assessment establishes the extent of the thrombus and the patency of the remaining portomesenteric axis.

\section{Outcomes}

Outcomes of LT for patients with PVT are influenced by the grade of PVT as well as the surgical procedure performed. Regardless of extent of thrombosis, if an end to end porto-portal anastomosis was successfully performed in patients with PVT, the 1 and 5 year survival was similar to patients without PVT and ranging from $84-86 \%$ and $65 \%-80 \%$ respectively (11). A meta-analysis published recently demonstrated increased mortality in patients with PVT (14\%) when compared to those without PVT (7\% (OR 2.29; $95 \% \mathrm{Cl}, 1.43-3.68, \mathrm{p}<0.0001$ ). The 30 day mortality was higher in patients with complete occlusive vs partial non occlusive PVT (OR 5.65; $95 \% \mathrm{Cl} 2-15.96, p=0.001$ ) (29). Non physiological reconstruction is associated with a higher incidence of post-operative morbidity and mortality $(11,25)$.

\section{Anticoagulation}

Prospective data on need for post procedure anticoagulation is scarce. It may be prudent to administer a short course of fractionated heparin in the early postoperative course, but long term anticoagulation should be reserved for patients with non-physiological restoration of portal flow (11).

\section{ADVANCEMENTS IN ARTERIAL RECONSTRUCTION}

In the initial years of liver transplantation, complication rates post hepatic arterial reconstruction ranged between $15-25 \%$, establishing this as a crucial step in this complex procedure (30). Complications were generally associated with significant morbidity, graft loss and commonly death. LDLT was especially challenging due to variable vascular anatomy, sizes, hemodynamics and differing orientation of the vascular structures between the graft and the recipient.

Numerous technical advancements, foremost being the standardization and application of microsurgical techniques to anastomosis, the complication rates have now declined to less than $3-5 \%$ in most high volume centers (31).
The main factors responsible for a successful reconstruction are; correct choice of inflow vessel, minimal periarterial dissection allowing for a higher quality of recipient vessel at the time of anastomosis and most crucially a standardized anastomotic technique.

More than $90 \%$ of arterial anastomosis are anatomical ones, referring to recipient hepatic arteries (RHA/LHA/CHA/PHA) used for anastomosis to the graft hepatic artery. Anatomic reconstruction allows for correct size matching, proper orientation and technical ease. Alternate non anatomical inflows may be obtained when anatomic reconstruction is not feasible from the splenic artery (fig. 10), right gastroepiploic, gastroduodenal, jejunal arteries or a radial artery interposition graft from the aorta (32). Reconstruction using non anatomical inflow was recently shown to not be associated with arterial complications, graft or patient survival (33).

High hilar dissection as initially propagated by the Korean groups has become the standard technique of performing recipient hepatectomy and serves to save both the biliary blood supply and maximal length of the recipient arterial tree (34). Early placement of a non-traumatic bulldog clamp on the common hepatic artery minimizes the risk of arterial dissection (35).

Arterial anastomosis may be performed under a microscope or under loupe magnification. Transplant and HPB surgeons are not very well versed in working under a microscope and additional specialized microsurgical training s required for them to reliably perform the anastomosis confidently (36). The operating microscope provides the benefit of a sound evaluation of donor and recipient vessels to search for and eliminate dissection of the intima, flaps or soft thrombi which

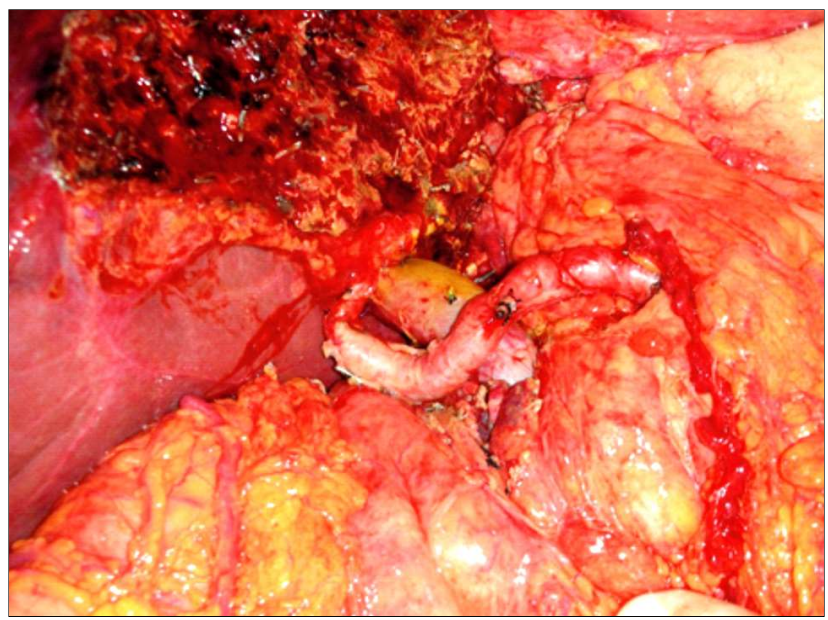

Figure 10 - Utilization of Splenic artery as the arterial inflow 
may lead to post-operative hepatic artery thrombosis. Alternatively, there is now growing evidence that suggests reconstruction under loupe provides equitable outcomes with the added benefit of convenience and ease of use as compared to the logistical difficulties associated with a microscope $(31,37)$.

An expanding donor pool which includes older donors and recipients with portal vein thrombosis or having undergone TARE/TACE mean the quality of graft and recipient arteries may be suboptimal. TARE/TACE which have been linked to a higher incidence of hepatic arterial dissection. (38) Evolution of techniques to tackle hepatic arterial dissection have been described by Banshodani and Gupta $(39,40)$. Gupta et al proposed a useful classification for hepatic arterial dissection that may be used as an aid to surgical management including at technique to approximate the dissected arterial intima to the media as a way of reversing dissection (40).

Anastomosis may be performed using an interrupted, continuous or continuous suture and interrupted tie technique may be performed. Continuous anastomosis provides the potential advantages of speed and the ability to easily adapt to size mismatches. However, care must be taken in cases of arterial dissection and the development of a purse string like effect. A back wall first technique has been described in cases of short graft hepatic arterial stumps that might preclude rotation (41).

In case of dual HA supply, reconstruction of multiple arteries is more often sought for right lobe grafts as compared to left lobe grafts. A useful intraoperative trick is to divide the smaller artery earlier to the larger artery during graft harvesting and anastomosing it after anastomosing the larger artery during reconstruction. This allows for observation of (if any) brisk pulsatile backflow in the smaller artery both after division as well as after anastomosis of the larger artery indicating presence of adequate intra-hepatic arterial plexuses (fig. 11).

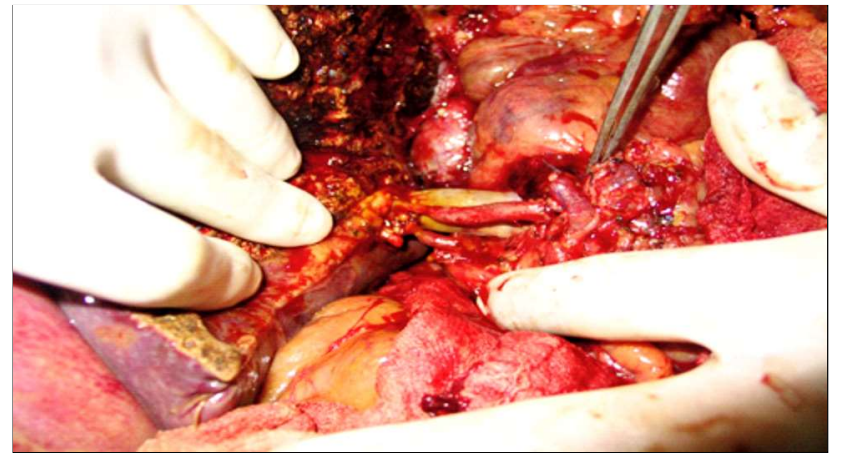

Figure 11 - Dual arterial anastomosis in a right lobe graft
Post anastomotic arterial flow may be compromised by kinking, undue angulation, spasm or development of acute thrombosis at the anastomotic site. Arterial spasm is commonly encountered especially if there is excessive dissection or handling of recipient vessels. Arterial spasm can be reversed by watchful waiting for spontaneous resolution, portal vein clamping for 5 to 10 seconds to allow for compensatory increase in arterial flow or alternatively by administration of PGE1 (42). If there is presence of kinking or angulation, there exists little option but to revise the HA anastomosis.

\section{ADVANCEMENTS IN INFLOW MODULATION}

Transplant surgeons have gained significant experience and understanding of arterial, venous and biliary anatomy of the liver and donors are now seldom rejected for anatomical variations (4). Graft size is a limiting factor for prospective liver donation. The traditionally accepted safe lower limits of good-quality livers that are sufficient are a $30 \%$ future liver remnant after donor hepatectomy (43) and a $40 \%$ standard liver volume equating to a GRWR of $0.8 \%$ ) for a transplant recipient (44). Liver volumes below this threshold were considered to impact both donor safety as well as recipient outcomes.

While certain groups reported acceptable outcomes with GRWR $<0.8 \%$ without the need for portal flow modulation (45-47), there existed a general skepticism to utilize smaller grafts for fear of development of small for size syndrome (SFSS). SFSS manifests as prolonged post-operative hyperbilirubinemia, intractable ascites, sepsis and eventually increased mortality (48). A number of factors are known to additionally contribute to development of SFFS including degree of portal hypertension, portal pressure and portal vein flow velocity, venous outflow reconstruction, MELD and the quality of graft (49). A new concept of a "Smallfor-Flow" syndrome (SFFS) serves to explain the pathophysiology of SFSS as a difference between liver mass and portal flow with the focus on matching the portal flow to the amount of liver tissue (50).

Portal inflow modulation (PIM) to modulate the pressure and flow velocity of portal blood to the graft has been increasingly used to prevent the graft from injury second to portal hypertension. Combined with liberal PIM, grafts with GRWR $<0.6 \%$ have shown equivalent graft and patient outcomes when compared to larger grafts with GRWR $>0.8 \%(51)$.

A normal healthy liver has a portal flow of approximately $100 \mathrm{ml} / \mathrm{min} / 100 \mathrm{gm}$ graft weight. Graft portal 
flow greater than $250 \mathrm{ml} / 100 \mathrm{~g} / \mathrm{min}$ has been shown to trigger the pathophysiology of small for size syndrome (SFSS) (52). Other studies report portal pressures over $15 \mathrm{mmHg}$ being detrimental to the graft (53).

There are three main strategies for modulation of portal inflow; splenic artery ligation, splenectomy and creation of portosystemic shunts.

\section{SPLENIC ARTERY LIGATION}

Splenic artery ligation (SAL) was first described by Makuuchi as a method to reverse post transplantation thrombocytopenia (54). Nishida et al had previously demonstrated a $20-30 \%$ decrease in PVP and PVF after occlusion of the splenic venous blood flow (55). SAL is being utilized as a useful method to prevent graft damage from mild to moderate portal hyper perfusion (fig. 12) (56). SAL alone proves incapable of reducing graft damage when PVF $>400$ $\mathrm{ml} / \mathrm{min} / 100 \mathrm{~g}$ graft weight, PVP $>20 \mathrm{~mm} \mathrm{Hg}$ or GRWR lower than 0.70 .

\section{SPLENIC DEVASCULARIZATION}

A more aggressive form of SAL in the form of splenic devascularization involving ligation of the splenic artery, right gastroepiploic artery and division of the gastrosplenic ligament including the short gastric arteries has been proposed by Moon et al as a means to reduce portal flow more than a standard SAL (57). The attendant benefits of this procedure are a significant decrease in complications as compared to splenectomy ( $1.6 \%$ vs $11.3 \%)$.

\section{SPLENECTOMY}

Splenectomy is recognized to be more efficacious than SAL in reducing PVP (58). Splenic size has been found to correlate with the degree of portal hypertension (59). Splenectomy has been shown to decrease

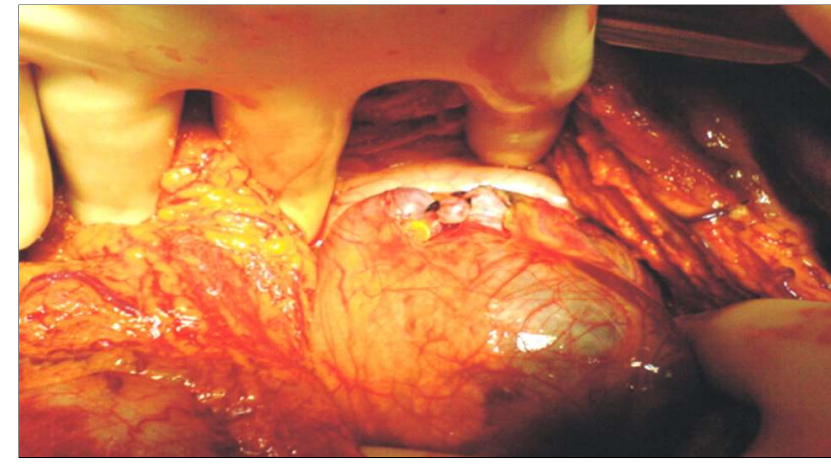

Figure 12 - Splenic Artery Ligation to decrease portal vein inflow
PVP by an average of $4 \mathrm{~mm}$ hg (60). A number of groups from Japan have reported consistently good outcomes utilizing splenectomy for PIM $(61,62)$. Splenectomy is however associated with an increase in incidence of post-operative hemorrhage (up to $18.9 \%$ ), lethal infectious complications including overwhelming post splenectomy sepsis (up to $10 \%$ ), new onset portal vein thrombosis (upto $40 \%$ ) and leak from pancreatic stump $(1-5 \%)(63,64)$. Technical advancements such as dissection using vessel sealing systems and endo-stapling devices along with gentle handling and mobilization have led to a decrease in the complication rate (60).

\section{PORTO-SYSTEMIC SHUNTS}

Around $40 \%$ of cirrhotics develop compensatory porto-systemic shunts with the frequency increasing with increasing severity of cirrhosis (65). Spontaneous or surgically created PSS are the most efficient method of lowering portal hypertension.

A number of portosystemic shunts develop spontaneously during the natural history of portal hypertension (66). These shunts reduce portal hypertension and blood loss and should be preserved during recipient hepatectomy phase of transplant. PSS serve as double edged swords as uncontrolled lowering of portal flow may lead to a devastating portal steal syndrome with graft dysfunction $(67,68)$. During acute cellular rejection, as the graft resistance increases uninterrupted portosystemic shunts are likely to drain blood away from the graft worsening ischemic damage (69).

Calibrated hemiportal shunts to modulate portal flow were thus proposed (70). Hemiportocaval shunts provide an alternative to splenectomy where GRWR $<0.7 \%$ and significant reduction in PVP is required. The purported benefits of the HPCS include a greater reduction in PV flow, avoidance of splenectomy related complications, relative ease in performing the procedure, shorter operating time and the potential for reversibility (50). In a recent study Soin et al demonstrated a SFSS rate of $4.2 \%$ and $3.7 \%$ in grafts with GRWR of $0.54-0.69 \%$ and $0.70-0.74 \%$ with liberal usage of HPCVS. Shunt flow was documented as $33-50 \%$ of the total portal venous flow. On follow up, surgical shunts showed spontaneous closure rates of $18.8 \%$ at 3 months and $61.5 \%$ at 5 years $(71)$.

Pharmacologic interventions to lower portal flow offer some promise especially in the post operative period. A randomized control trial by Troisi showed somatostatin reduced portal pressure by up to $29 \%$. (72). 


\section{WHEN TO USE WHICH}

SAL is a safe first line modulation for portal flow modulation that is useful in lower degrees of portal hypertension. More data is needed to define the place of splenic devascularization in this clinical space. With small grafts (GRWR < 0.7) and severe portal hypertension, splenectomy and HPCS are excellent interventions for graft protection.

\section{ADVANCEMENTS IN BILIARY RECONSTRUCTION}

Biliary complications still represent the biggest thorn in the side of living donor liver transplantation. Despite numerous advancements and technical refinements the incidence of biliary complications remain in the range of $7.4 \%$ to $39 \%(73,74)$.

\section{Evaluation of biliary anatomy}

Minimizing biliary complications begins from the adequate planning in the preoperative stage with donor selection and detailed evaluation of biliary anatomy. Magnetic resonance cholangiography is performed as a standard part of preoperative donor evaluation. There exists significant discordance between MRC and IOC visualization of biliary anatomy (75). Therefore most centers therefore continue to perform real time IOC, utilizing a radio opaque marker to tag the site of division of the biliary tree to minimize the number of graft duct openings without compromising on donor safety (4). With the advent of minimally invasive and robotic donor hepatectomy, indocyanine green fluorescence cholangiography is increasingly being used an adjunct to delineate and map three dimensional biliary anatomy (76). Huang's classification of biliary anatomy is used as the standard classification for preoperative planning (77).

\section{Safe isolation of graft hepatic duct}

The development of the high hilar dissection and the Glissonean sheath approach aimed to minimize dissection of the donor hilum without disturbing the peribiliary plexus $(34,78)$. The 'Glissonean bundle vessel subtraction technique' left a thick cover of sheath around the graft hepatic duct that preserved the extensive perihilar vascular network, provided a sturdy wall to hold sutures and prevents the retraction of small hepatic duct keeping it in its natural lie to facilitate a twist-free anastomoses $(34,79)$. Donors with multiple ducts $(\geq 2)$ can also be safely accepted with this technique. The right hepatic artery is a major artery supplying the hilar plate and bile ducts (80) and keeping the plane between the RHA and the bile duct has been advocated as a way to minimize ductal ischemia $(81,82)$.

\section{Biliary reconstruction techniques}

Over the past few decades numerous technical advancements have been made while keeping in mind the fundamental principles of biliary anastomosis which include tension free anastomosis, proper placement of sutures, mucosa to mucosa approximation and an uninterrupted blood supply.

\section{Duct to duct vs Roux en $Y$ \\ hepaticojejunostomy $(\mathrm{HJ})$}

In the early years, RYHJ was the standard technique of biliary reconstruction because of its wide applicability, ease of use, wide applicability allowing consistent tension free anastomosis and the supposed rich vascular supply of the jejunum (83). RYHJ has however been replaced by duct-duct anastomosis as the preferred procedure because of its technical ease, shorter operative time, and a more physiological nature minimizing enteric contamination (84). DDA also allows for early resumption of oral intake and easy endoscopic intervention in case of biliary complications. There has been no consensus with a meta-analysis and systemic review showing conflicting results regarding the superiority of one technique over the other. $(85,86)$. No matter which technique is utilized, the incidence of biliary complications increases with number of ductal openings (87).

\section{Stents - internal/external}

Historically, T-tubes were used across CC in a bid to reduce biliary complications with mixed results. While patient related discomfort was a constant, the clinical benefit to the patient was questionable. A meta analysis on its utility favored abandonment of $T$ tubes during liver transplantation. The position of $T$ tubes was soon taken by internal biliary stents (88). Stents were thought to be adjuncts to lower the rates of biliary leaks and strictures again with mixed results. While a recently conducted RCT demonstrated a sizeable increase in biliary complications in the transduodenal internal biliary stent group (89), groups 
from Asan medical center have shown a distinct decrease in the incidence of biliary complications after external biliary stenting (4).

Certain eastern groups have shown consistent good results with transcholedochal interno-external biliary stents $(90,91)$. Technically, an ideal DDA anastomosis avoids luminal narrowing while minimizing inter suture tissue edema. Common errors include overly deep, thick, tensional, or loose stitches on the bile ducts. Multiple, small and deep lying ducts however continue to be risk factors for complications despite optimum technique. External drainage tubes offer several advantages. Firstly, it prevents catching of the posterior bile ductal wall during anastomosis of smaller ducts. It maintains patency of the ductal system and reduces intraductal pressure at the site of anastomosis. Additionally bile quality and output provides information on graft function and allows for cholangiography in case of biliary complications. There does however exist risk of bile leak and biliary sepsis during or after removal of the catheter (92).

\section{Telescopic reconstruction or mucosal eversion}

A novel technique from the Korean group involved anastomosis of the graft duct to the inner epithelial layer of the recipient duct and not to the whole duct, thereby in a way "telescoping" one duct in another (93). The telescoping allows for a ready management of potential size mismatched ducts along with utilizing the inner richly vascular endothelial layer for anastomosis.

A similar technique was described by $\mathrm{Vij}$ et al (94) with the addition of corner sparing sutures to mucosal eversion lowered biliary complication rate in his series to $3.7 \%$. With peribiliary arterial plexuses running at 3 and 9 o clock location avoidance of placement of sutures at corners seems prudent and scientifically sound.

\section{Microsurgery}

Microsurgical biliary reconstruction performed in certain centers has shown excellent results. The purported advantages include enhanced visualization of the operative field under magnification to minimize trauma to the bile duct epithelium, preservation of vascularity and more precise placement of sutures during anastomosis especially when dealing with multiple ducts (95). Lin et al demonstrated an overall biliary complication rate of $8.9 \%$ using microsurgical

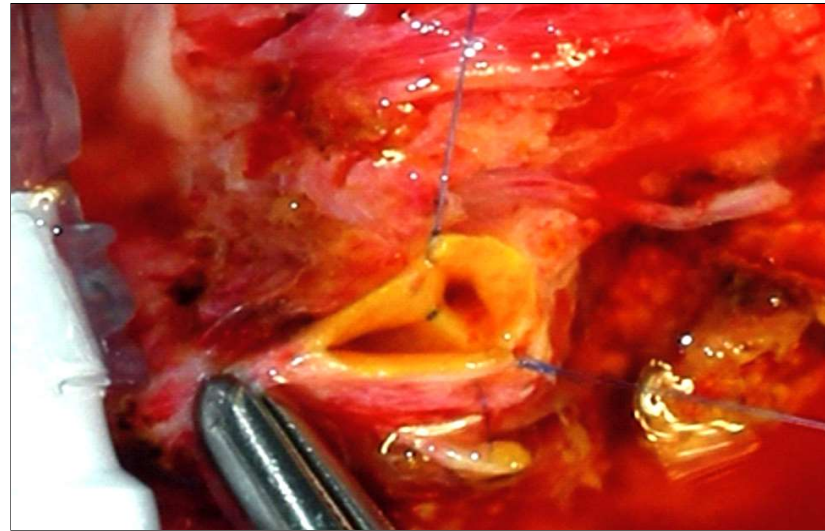

Figure 13 - Back wall plasty of 2 closely positioned bile ducts to allow for a single anastomosis

techniques with progressively improving results after the initial learning curve was overcome (96).

\section{Management of multiple bile ducts}

The approach towards choosing the number and type of anastomosis when multiple graft ducts are encountered has become fairly standardized over the past decade. An excellent detailed description of the various graft-recipient ductal scenarios has been described by Lin et al in a recently published review and is worthy of the reader's consideration. (96) When the two orifices are close together, a ductoplasty (if achieved without tension) performed followed by a single anastomosis seems to be the preferred method of biliary reconstruction (fig. 13). However, ductoplasty performed for ducts that are further apart than the diameter of the larger duct or lie in different planes are doomed to fail (fig. 14) (4).

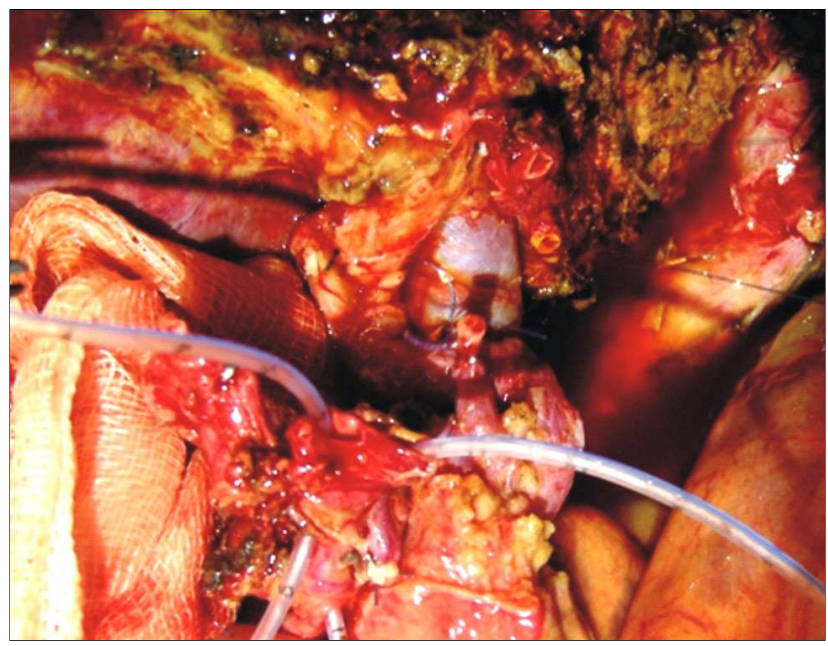

Figure 14 - 2 separate ductal anastomosis planned for 2 ducts far apart on the graft side 


\section{Conflict of interest}

No financial disclosures. No conflict of interests.

\section{REFERENCES}

1. Lee S, Park K, Hwang S, Lee Y, Choi D, Kim K, et al. Congestion of right liver graft in living donor liver transplantation. Transplantation. 2001;71(6):812-4.

2. Takahashi M, Fukumoto T, Kido M, Tsuchida S, Takebe A, Kuramitsu $\mathrm{K}$, et al. Morphometric analysis of conformational changes in hepatic venous system after right lobe living donor liver transplantation. Hepatol Res. 2011;41(4):318-27.

3. Lee SG. Techniques of reconstruction of hepatic veins in livingdonor liver transplantation, especially for right hepatic vein and major short hepatic veins of rightlobe graft. J Hepatobiliary Pancreat Surg. 2006;13(2):131-8.

4. Lee SG. A complete treatment of adult living donor liver transplantation: A review of surgical technique and current challenges to expand indication of patients. Am J Transplant. 2015;15(1):17-38.

5. Hwang S, Jung DH, Ha TY, Ahn CS, Moon DB, Kim KH, et al. Usability of ringed polytetrafluoroethylene grafts for middle hepatic vein reconstruction during living donor liver transplantation. Liver Transplant. 2012;18(8):955-65.

6. Lee KW, Lee DS, Lee HH, Joh JW, Choi SH, Heo JS, et al. Interpostion vein graft in living donor liver transplantation. In Transplantation Proceedings. Transplant Proc. 2004;36(8):2261-2.

7. Goja S, Yadav SK, Roy R, Soin AS. A retrospective comparative study of venous vs nonringed expanded polytetrafluoroethylene extension grafts for anterior sector outflow reconstruction in right lobe living donor liver transplantation. Clin Transplant. 2018; 32(8):e13344.

8. Pamecha V, Pattnaik B, Sinha PK, Patil NS, Mohapatra N, Sasturkar SV, et al. Single Orifice Outflow Reconstruction: Refining the Venous Outflow in Modified Right Lobe Live Donor Liver Transplantation. J Gastrointest Surg. 2020 Aug 17. Online ahead of print.

9. Sugawara Y, Makuuchi M, Akamatsu N, Kishi Y, Niiya T, Kaneko J, et al. Refinement of venous reconstruction using cryopreserved veins in right liver grafts. Liver Transplant. 2004;10(4):541-7.

10. Dayangac M, Taner CB, Balci D, Memi I, Yaprak O, Akin B, et al. Use of middle hepatic vein in right lobe living donor liver transplantation. Transpl Int. 2010;23(3):285-91.

11. Francoz $C$, Valla D, Durand F. Portal vein thrombosis, cirrhosis, and liver transplantation. J Hepatol. 2012;57(1):203-12.

12. Ghabril M, Agarwal S, Lacerda M, Chalasani N, Kwo P, Joseph Tector A. Portal vein thrombosis is a risk factor for poor early outcomes after liver transplantation: Analysis of risk factors and outcomes for portal vein thrombosis in waitlisted patients. Transplantation. 2016;100(1):126-33.

13. Montenovo MI, Rahnemai-Azar A, Reyes J, Perkins J. Clinical impact and risk factors of portal vein thrombosis for patients on wait list for liver transplant. Exp Clin Transplant. 2018;16(2):166-71.

14. Northup PG, Argo CK, Shah N, Caldwell SH. Hypercoagulation and thrombophilia in nonalcoholic fatty liver disease: Mechanisms, human evidence, therapeutic implications, and preventive implications. Semin Liver Dis. 2012;32(1):39-48.

15. Nery F, Chevret S, Condat B, de Raucourt E, Boudaoud L, Rautou PE, et al. Causes and consequences of portal vein thrombosis in 1,243 patients with cirrhosis: Results of a longitudinal study. Hepatology. 2015;61(2):660-7.

16. Chen H, Turon F, Hernández-Gea V, Fuster J, Garcia-Criado A, Barrufet $\mathrm{M}$, et al. Nontumoral portal vein thrombosis in patients awaiting liver transplantation. Liver Transpl. 2016;22(3):352-65.

17. Luca A, Miraglia R, Caruso S, Milazzo M, Sapere C, Maruzzelli L, et al. Short- and longterm effects of the transjugular intrahepatic portosystemic shunt on portal vein thrombosis in patients with cirrhosis. Gut. 2011;60(6):846-52.

18. Yerdel MA, Gunson B, Mirza D, Karayalçin K, Olliff S, Buckels J, et al. Portal vein thrombosis in adults undergoing liver transplantation:
Risk factors, screening, management, and outcome. Transplantation. 2000;69(9):1873-81.

19. Jamieson N V. Changing perspectives in portal vein thrombosis and liver transplantation. Transplantation. 2000;69(9):1772-4.

20. Charco R, Fuster J, Fondevila C, Ferrer J, Mans E, García-Valdecasas JC. Portal vein thrombosis in liver transplantation. In: Transplantation Proceedings. 2005. p. 3904-5.

21. Bhangui $P$, Lim $C$, Levesque E, Salloum $C$, Lahat E, Feray $C$, et al. Novel classification of non-malignant portal vein thrombosis: A guide to surgical decision-making during liver transplantation. J Hepatol. 2019;71(5):1038-50.

22. Bhangui P, Lim C, Salloum C, Andreani P, Sebbagh M, Hoti E, et al. Caval inflow to the graft for liver transplantation in patients with diffuse portal vein thrombosis: A 12-Year experience. Ann Surg. 2011;254(6):1008-16.

23. Tzakis AG, Kirkegaard P, Pinna AD, Jovine E, Misiakos EP, Maziotti $A$, et al. Liver transplantation with cavoportal hemitransposition in the presence of diffuse portal, vein thrombosis. Transplantation. 1998;65(5):619-24.

24. Erhard J, Lange R, Giebler R, Rauen U, de Groot H, Eigler FW. Arterialization of the portal vein in orthotopic and auxiliary liver transplantation: A report of three cases. Transplantation. 1995; 60(8):877-9.

25. Hibi T, Nishida S, Levi DM, Selvaggi G, Tekin A, Fan J, et al. When and why portal vein thrombosis matters in liver transplantation: $A$ critical audit of 174 cases. Ann Surg. 2014;259(4):760-6

26. Robles R, Fernández JÁ, Hernández Q, Marín C, Ramírez P, SánchezBueno $\mathrm{F}$, et al. Eversion thromboendovenectomy in organized portal vein thrombosis during liver transplantation. Clin Transplant. 2004;18(1):79-84.

27. Koh PS, Chan SC, Chok KSH, Sharr WW, Wong TCL, Sin SL, et al. The friendly incidental portal vein thrombus in liver transplantation. Liver Transplant. 2015;21(7):944-52.

28. Mori A, lida T, Iwasaki J, Ogawa K, Fujimoto Y, Uemura T, et al. Portal vein reconstruction in adult living donor liver transplantation for patients with portal vein thrombosis in single center experience. J Hepatobiliary Pancreat Sci. 2015;22(6):467-74.

29. Zanetto A, Rodriguez-Kastro KI, Germani G, Ferrarese A, Cillo U, Burra $P$, et al. Mortality in liver transplant recipients with portal vein thrombosis - an updated metaanalysis. Transpl Int. 2018;31(12): 1318-29.

30. Broelsch CE, Whitington PF, Emond JC, Heffron TG, Thistlethwaite $J R$, Stevens $L$, et al. Liver transplantation in children from living related donors: Surgical techniques and results. Ann Surg. 1991; 214(4):428-37; discussion 437-9.

31. Ikegami T, Yoshizumi T, Uchiyama $H$, Soejima $Y$, Harada N, Maehara $Y$. Hepatic artery reconstruction in living donor liver transplantation using surgical loupes: Achieving low rate of hepatic arterial thrombosis in 741 consecutive recipients-tips and tricks to overcome the poor hepatic arterial flow. Liver Transplant. 2017; 23(8):1081-2.

32. Jung DH, Park CS, Ha TY, Song GW, Park GC, Cho YP, et al. Placement of an aortohepatic conduit as an alternative to standard arterial anastomosis in liver transplantation. Ann Transplant. 2018;23:61-5

33. Rhu J, Kim JM, Choi GS, David Kwon CH, Joh JW. Impact of Extraanatomical Hepatic Artery Reconstruction During Living Donor Liver Transplantation on Biliary Complications and Graft and Patient Survival. Transplantation. 2019;103(9):1893-902.

34. Lee KW, Joh JW, Kim SJ, Choi SH, Heo JS, Lee HH, et al. High hilar dissection: New technique to reduce biliary complication in living donor liver transplantation. Liver Transplant. 2004;10(9):1158-62.

35. Duffy JP, Hong JC, Farmer DG, Ghobrial RM, Yersiz H, Hiatt JR, et al. Vascular Complications of Orthotopic Liver Transplantation: Experience in More than 4,200 Patients. J Am Coll Surg. 2009; 208(5):896-903.

36. Mokhtari P, Meybodi AT, Benet A, Lawton MT. Microvascular anastomosis: Proposition of a learning curve. Oper Neurosurg. 2019;16(2):211-6.

37. Yagi T, Shinoura S, Umeda Y, Sato D, Yoshida R, Yoshida K, et al. Surgical rationalization of living donor liver transplantation by 
abolition of hepatic artery reconstruction under a fixed microscope. Clin Transplant. 2012;26(6):877-83.

38. Lin TS, Chiang YC, Chen CL, Concejero AM, Cheng YF, Wang CC, et al. Intimal dissection of the hepatic artery following transarterial embolization for hepatocellular carcinoma: An intraoperative problem in adult living donor liver transplantation. Liver Transplant. 2009;15(11):1553-6.

39. Banshodani M, Tashiro H, Onoe T, Ide K, Ohdan H. Long-term outcome of hepatic artery reconstruction during living-donor liver transplantation. Transplant Proc. 2011;43(5):1720-4.

40. Agarwal S, Dey R, Pandey Y, Verma S, Gupta S. Managing Recipient Hepatic Artery Intimal Dissection During Living Donor Liver Transplantation. Liver Transplant. 2020;26(11):1422-9.

41. Lee CF, Lu JCY, Zidan A, Lee CS, Wu TH, Chan KM, et al. Microscope-assisted hepatic artery reconstruction in adult living donor liver transplantation-A review of 325 consecutive cases in a single center. Clin Transplant. 2017;31(2). Epub 2017 Jan 2.

42. Balci D, Ahn CS. Hepatic artery reconstruction in living donor liver transplantation. Curr Opin Organ Transplant. 2019;24(5):631-6.

43. Fan ST, Lo CM, Liu CL, Yong BH, Chan JKF, Ng IOL. Safety of donors in live donor liver transplantation using right lobe grafts. Arch Surg. 2000;135(3):336-40.

44. Kiuchi T, Kasahara M, Uryuhara K, Inomata Y, Uemoto S, Asonuma $\mathrm{K}$, et al. Impact of graft size mismatching on graft prognosis in liver transplantation from living donors. Transplantation. 1999;67(2): 321-7.

45. Selzner M, Kashfi A, Cattral MS, Selzner N, Greig PD, Lilly L, et al. A graft to body weight ratio less than 0.8 does not exclude adult-toadult right-lobe living donor liver transplantation. Liver Transplant. 2009;15(12):1776-82.

46. Moon JI, Kwon CHD, Joh JW, Jung GO, Choi GS, Park JB, et al. Safety of small-for-size grafts in adult-to-adult living donor liver transplantation using the right lobe. Liver Transplant. 2010; 16(7):864-9.

47. Lee SD, Kim SH, Kim YK, Lee SA, Park SJ. Graft-to-recipient weight ratio lower to $0.7 \%$ is safe without portal pressure modulation in right-lobe living donor liver transplantation with favorable conditions. Hepatobiliary Pancreat Dis Int. 2014;13(1):18-24.

48. Kiuchi T, Tanaka K, Ito T, Oike F, Ogura Y, Fujimoto Y, et al. Small-forsize graft in living donor liver transplantation: How far should we go? Liver Transpl. 2003;9(9):S29-35

49. Ikegami T, Onda S, Furukawa K, Haruki K, Shirai Y, Gocho T. Smallfor-size graft, small-for-size syndrome and inflow modulation in living donor liver transplantation. J Hepatobiliary Pancreat Sci. 2020; 27(11):799-809. Epub 2020 0ct 12.

50. Orue-Echebarria MI, Lozano P, Olmedilla L, Sabrido JLG, Asencio JM. "Small-for-Flow" syndrome: concept evolution. J Gastrointest Surg. 2020;24(6):1386-1391. Epub 2020 Apr 20.

51. Wong TC-L, Fung JYY, Cui TYS, Sin SL, Ma KW, She BWH, et al. The Risk of Going Small: Lowering GRWR and Overcoming Small-ForSize Syndrome in Adult Living Donor Liver Transplantation. Ann Surg. 2020 Mar 20. Online ahead of print.

52. Sainz-Barriga M, Reyntjens K, Costa MG, Scudeller L, Rogiers X Wouters $P$, et al. Prospective evaluation of intraoperative hemodynamics in liver transplantation with whole, partial and DCD grafts. Am J Transplant. 2010;10(8):1850-60.

53. Ogura Y, Hori T, El Moghazy WM, Yoshizawa A, Oike F, Mori A, et al. Portal pressure $<15 \mathrm{~mm} \mathrm{Hg}$ is a key for successful adult living donor liver transplantation utilizing smaller grafts than before. Liver Transplant. 2010;16(6):718-28.

54. Matsukura A, Kita Y, Harihara Y, Kubota K, Takayama T, Kawarasaki $\mathrm{H}$, et al. Is splenic artery ligation effective for thrombocytopenia early after liver transplantation? In: Transplantation Proceedings. Transplant Proc; 1999. p. 2906-7.

55. Nishida O, Moriyasu F, Nakamura T, Ban N, Miura K, Sakai M, et al. Interrelationship between splenic and superior mesenteric venous circulation manifested by transient splenic arterial occlusion using a balloon catheter. Hepatology. 1987;7(3):442-6.

56. Lo CM, Liu CL, Fan ST. Portal hyperperfusion injury as the cause of primary nonfunction in a small-for-size liver graft-successful treatment with splenic artery ligation. Liver Transplant. 2003;9(6):626-8.
57. Moon DB, Lee SG, Hwang S, Ahn CS, Kim KH, Ha TY, et al. Splenic devascularization can replace splenectomy during adult living donor liver transplantation - a historical cohort study. Transpl Int. 2019; 32(5):535-45

58. Shimada M, ljichi H, Yonemura Y, Harada N, Shiotani S, Ninomiya $\mathrm{M}$, et al. The impact of splenectomy or splenic artery ligation on the outcome of a living donor adult liver transplantation using a left lobe graft. Hepatogastroenterology. 2004;51(57):625-9.

59. Cheng YF, Huang TL, Chen TY, Concejero A, Tsang LLC, Wang CC, et al. Liver graftto-recipient spleen size ratio as a novel predictor of portal hyperperfusion syndrome in living donor liver transplantation. Am J Transplant. 2006;6(12):2994-9.

60. Ikegami T, Toshima T, Takeishi K, Soejima Y, Kawanaka H, Yoshizumi $\mathrm{T}$, et al. Bloodless splenectomy during liver transplantation for terminal liver diseases with portal hypertension $\mathrm{J}$ Am Coll Surg. 2009;208(2):e1-4. Epub 2008 Dec 12.

61. Yao S, Kaido T, Yagi S, Uozumi R, Iwamura S, Miyachi Y, et al. Impact of imbalanced graft-to-spleen volume ratio on outcomes following living donor liver transplantation in an era when simultaneous splenectomy is not typically indicated. Am J Transplant. 2019; 19(10):2783-94.

62. Yoshizumi T, Taketomi A, Soejima Y, Ikegami T, Uchiyama H, Kayashima $\mathrm{H}$, et al. The beneficial role of simultaneous splenectomy in living donor liver transplantation in patients with small-for-size graft. Transpl Int. 2008;21(9):833-42.

63. Ito $\mathrm{K}$, Akamatsu N, Ichida A, Ito D, Kaneko J, Arita J, et al. Splenectomy is not indicated in living donor liver transplantation. Liver Transplant. 2016;22(11):1526-35.

64. Kurata N, Ogura $Y$, Ogiso $S$, Onishi $Y$, Kamei H, Kodera $Y$. Splenectomy in living donor liver transplantation and risk factors of portal vein thrombosis. Hepatobiliary Pancreat Dis Int. 2019; 18(4):337-42.

65. Zhou HY, Chen TW, Zhang XM, Jing ZL, Zeng NL, Zhai ZH. Patterns of portosystemic collaterals and diameters of portal venous system in cirrhotic patients with hepatitis B on magnetic resonance imaging: Association with Child-Pugh classifications. Clin Res Hepatol Gastroenterol. 2015;39(3):351-8.

66. Ito K, Higuchi M, Kada T, Mitchell DG, Nomura S, Honjo K, et al. CT of Acquired Abnormalities of the Portal Venous System. Radiographics. 1997;17(4):897-917.

67. Moon DB, Lee SG, Kim KH, Ahn CS, Hwang S, Park KM, et al. The significance of complete interruption of large spontaneous portosystemic collaterals in adult living donor liver transplantation as a graft salvage procedure. Transpl Int. 2008;21(7):698-700.

68. Troisi R, Cammu G, Militerno G, De Baerdemaeker L, Decruyenaere J, Hoste E, et al. Modulation of Portal Graft Inflow: A Necessity in Adult Living-Donor Liver Transplantation? Ann Surg. 2003;237(3): $429-36$.

69. Morioka D, Egawa H, Kasahara M, Ito T, Haga H, Takada Y, et al. Outcomes of adult-toadult living donor liver transplantation: A single institution's experience with 335 consecutive cases. Ann Surg. 2007; 245(2):315-25

70. Paskonis M, Jurgaitis J, Mehrabi A, Kashfi A, Fonouni H, Strupas $\mathrm{K}$, et al. Surgical strategies for liver transplantation in the case of portal vein thrombosis - Current role of cavoportal hemitransposition and renoportal anastomosis. Clin Transplant. 2006;20(5): 551-62.

71. Soin AS, Yadav SK, Saha SK, Rastogi A, Bhangui P, Srinivasan T, et al. Is Portal Inflow Modulation Always Necessary for Successful Utilization of Small Volume Living Donor Liver Grafts? Liver Transplant. 2019;25(12):1811-21.

72. Troisi RI, Vanlander A, Giglio MC, van Limmen J, Scudeller L, Heyse $B$, et al. Somatostatin as inflow modulator in liver-transplant recipients with severe portal hypertension: A randomized trial. Ann Surg. 2019;269(6):1025-33.

73. Akamatsu N, Sugawara Y, Hashimoto D. Biliary reconstruction, its complications and management of biliary complications after adult liver transplantation: A systematic review of the incidence, risk factors and outcome. Transpl Int. 2011;24(4):379-92.

74. Olthoff KM, Merion RM, Ghobrial RM, Abecassis MM, Fair JH, Fisher $\mathrm{RA}$, et al. Outcomes of 385 adult-to-adult living donor liver trans- 
plant recipients: A report from the A2ALL consortium. Ann Surg. 2005;242(3):314-23, discussion 323-5.

75. Jeng KS, Huang CC, Lin CK, Lin CC, Chen KH, Chu SH. Repeated introperative cholangiography is helpful for donor safety in the procurement of right liver graft with supraportal right bile duct variants in living-donor liver transplantation. Transplant Proc. 2014;46(3):686-8.

76. Hong SK, Lee KW, Kim HS, Yoon KC, Ahn SW, Choi JY, et al. Optimal bile duct division using real-time indocyanine green nearinfrared fluorescence cholangiography during laparoscopic donor hepatectomy. Liver Transplant. 2017;23(6):847-52.

77. Huang TL, Cheng YF, Chen CL, Chen TY, Lee TY. Variants of the bile ducts: Clinical application in the potential donor of living-related hepatic transplantation. In: Transplantation Proceedings. 1996. p. 1669-70.

78. Ikegami T, Shimagaki T, Kawasaki J, Yoshizumi T, Uchiyama $H$, Harada N, et al. Eversion technique to prevent biliary stricture after living donor liver transplantation in the universal minimal hilar dissection era. Transplantation. 2017;101(1):e20-5.

79. Soin AS, Kumaran V, Rastogi AN, Mohanka R, Mehta N, Saigal S, et al. Evolution of a Reliable Biliary Reconstructive Technique in 400 Consecutive Living Donor Liver Transplants. J Am Coll Surg. 2010; 211(1):24-32.

80. Abu-Gazala S, Olthoff KM, Goldberg DS, Shaked A, Abt PL. En Bloc Hilar Dissection of the Right Hepatic Artery in Continuity with the Bile Duct: a Technique to Reduce Biliary Complications After Adult Living-Donor Liver Transplantation. J Gastrointest Surg. 2016; 20(4):765-71.

81. Soejima Y, Fukuhara T, Morita K, Yoshizumi T, Ikegami T, Yamashita $\mathrm{Y}$, et al. A simple hilar dissection technique preserving maximum blood supply to the bile duct in living donor liver transplantation. Transplantation. 2008;86(10):1468-9.

82. Taketomi A, Morita K, Toshima T, Takeishi K, Kayashima H, Ninomiya $M$, et al. Living donor hepatectomies with procedures to prevent biliary complications. J Am Coll Surg. 2010;211(4):456-64.

83. Zhang $\mathrm{S}$, Zhang $\mathrm{M}, \mathrm{Xia} \mathrm{Q}$, Zhang JJ. Biliary reconstruction and complications in adult living donor liver transplantation: Systematic review and meta-analysis. Transplant Proc. 2014; 46(1):208-15

84. Liu CL, Lo CM, Chan SC, Fan ST. Safety of duct-to-duct biliary reconstruction in rightlobe live-donor liver transplantation without biliary drainage. Transplantation. 2004;77(5):726-32.

85. Chok KSH, Lo CM. Systematic review and meta-analysis of studies of biliary reconstruction in adult living donor liver transplantation. ANZ J Surg. 2017;87(3):121-5

86. Zhang S, Zhang M, Xia Q, Zhang JJ. Biliary reconstruction and complications in adult living donor liver transplantation: Systematic review and meta-analysis. Transplant Proc. 2014; 46(1):208-15.

87. Chok KSH, Lo CM. Systematic review and meta-analysis of studies of biliary reconstruction in adult living donor liver transplantation. ANZ J Surg. 2017;87(3):121-5.

88. Sotiropoulos GC, Sgourakis G, Radtke A, Molmenti EP, Goumas K, Mylona S, et al. Orthotopic liver transplantation: T-tube or not Ttube? Systematic review and metaanalysis of results. Transplantation. 2009;87(11):1672-80.

89. Santosh Kumar KY, Mathew JS, Balakrishnan D, Bharathan VK, Thankamony Amma BSP, Gopalakrishnan U, et al. Intraductal Transanastomotic Stenting in Duct-to-Duct Biliary Reconstruction after Living-Donor Liver Transplantation: A Randomized Trial. J Am Coll Surg. 2017;225(6):747-54

90. Ikegami T, Yoshizumi T, Soejima Y, Ohira M, Maehara Y. Appropriate Use of Stents to Prevent Biliary Complications after Living Donor Liver Transplantation. J Am Coll Surg. 2018;226(2):201.

91. Hong SY, Hu XG, Lee HY, Won JH, Kim JW, Shen XY, et al. Longterm Analysis of Biliary Complications After Duct-to-Duct Biliary Reconstruction in Living Donor Liver Transplantations. Liver Transplant. 2018;24(8):1050-61.

92. Wang SF, Huang ZY, Chen XP. Biliary complications after living donor liver transplantation. Vol. 17, Liver Transplantation. John Wiley \& Sons, Ltd; 2011. p. 1127-36.

93. Kim SH, Lee KW, Kim YK, Cho SY, Han SS, Park SJ. Tailored telescopic reconstruction of the bile duct in living donor liver transplantation. Liver Transplant. 2010;16(9):1069-74.

94. Vij V, Makki K, Chorasiya VK, Sood G, Singhal A, Dargan P. Targeting the Achilles' heel of adult living donor liver transplant: Cornersparing sutures with mucosal eversion technique of biliary anastomosis. Liver Transplant. 2016;22(1):14-23.

95. Lin TS, Chen CL, Concejero AM, Yap AQ, Lin YH, Liu CY, et al. Section 9. technical details of microsurgical biliary reconstruction in living donor liver transplantation. In: Transplantation. Lippincott Williams and Wilkins; 2014. p. S34-6.

96. Lin TS, Co JS, Chen CL, Ong AD. Optimizing biliary outcomes in living donor liver transplantation: Evolution towards standardization in a high-volume center. Hepatobiliary Pancreat Dis Int. 2020;19(4): 324-7. 